\title{
Hyponatraemia and dehydration in severe malaria
}

\author{
M C English, C Waruiru, C Lightowler, S A Murphy, G Kirigha, K Marsh
}

\begin{abstract}
The prevalence and likely cause of hyponatraemia in severe childhood malaria were investigated. One hundred and thirty two children, 47 of whom had cerebral malaria, were prospectively recruited and serial simple indices of fluid and electrolyte balance and renal function monitored during admission. In 55\%, hyponatraemia (sodium $<135 \mathrm{mmol} / \mathrm{l}$ ) was present on admission. Hyponatraemia was pronounced (sodium $\leqslant 130$ $\mathrm{mmol} / \mathrm{l}$ ) in $21 \%$, and these children gained less weight during admission (mean weight gain $2 \cdot 4 \% v 4 \cdot 3 \%$ ) than children with a normal sodium (135-145 mmol/1). Overall, $31 \%$ of survivors were at least moderately dehydrated on admission $(5 \%$ weight gain by discharge). These children had higher plasma urea concentrations on admission (6.1 v $4.5 \mathrm{mmol} / \mathrm{l})$ and were more acidotic (mean base excess $-12 \cdot 1 v$ -8.0) than children who were not dehydrated. There were changes in simple indices of renal function between admission and discharge in children who survived (creatinine $65.7 v 37.9 \mu \mathrm{mol} / \mathrm{l}$ and urea $5.5 v 1.9 \mathrm{mmol} / \mathrm{l})$. The results suggest that dehydration is common in severe childhood malaria, that it may contribute to mild impairment in renal function, and that hyponatraemic children are less water depleted, showing appropriate rather than inappropriate secretion of antidiuretic hormone.

(Arch Dis Child 1996; 74: 201-205)
\end{abstract}

Keywords: hyponatraemia, malaria, syndrome of inappropriate antidiuretic hormone secretion.
CRC, KEMRI Kilifi

Unit, Kilifi, Kenya

C Waruiru

G Kirigha

Nuffield Department of Medicine, John Radcliffe Hospital, Headington, Oxford, United Kingdom

M C English K Marsh

Department of Rena Medicine, St. Bartholemew's Hospital, Smithfields, London, United Kingdom

C Lightowler

Correspondence to: Dr Mike English, CRC, KEMRI Kilifi Unit, PO Box 428, Kilifi, Kenya.

Accepted 15 November 1995 S A Murphy

caused by dehydration, is one of many factors that have been implicated in its pathogenesis. ${ }^{8}$ Recent work in Malawian children described metabolic acidosis that often resolved with administration of intravenous fluids, ${ }^{9}$ implying that dehydration, a recognised cause of metabolic acidosis, ${ }^{10}$ is found in childhood malaria.

For the clinician treading the path between SIADH, renal impairment, possible congestive cardiac failure secondary to severe anaemia, ${ }^{11}$ raised intracranial pressure in children in coma, ${ }^{12}$ and dehydration there is little published work to help in making decisions on fluid management in childhood malaria. Since it is usually an illness of short duration characterised by high fever, lethargy, and in severe cases the inability to drink, SIADH is an unlikely admission diagnosis. Therefore we prospectively examined children presenting with severe malaria to Kilifi District Hospital on the Kenyan coast to examine the prevalence and likely causes of hyponatraemia.

\section{Methods}

Children over 1 month of age, with a primary diagnosis of severe Plasmodium falciparum malaria admitted during June to September 1994, were eligible for inclusion in the study. Severe malaria was prospectively defined as prostration (an inability to sit if more than 1 year of age or to breast feed if less than 1 year), respiratory distress (indrawing or deep breathing), or coma (inability to localise to pain). ${ }^{13}$ Children were excluded if they had evidence of either concurrent pneumonia on chest $x$ ray, meningitis, or septicaemia, or were suffering from any of the following conditions: congenital heart disease, preceding developmental delay, chronic renal disease, kwashiorkor, tuberculosis, or symptomatic HIV infection.

Baseline investigations performed before the Hyponatraemia is common in acute childhood illness, being found in as many as $31 \%$ of cases of pneumonia, ${ }^{1} 50 \%$ of cases of meningitis, ${ }^{2}$ and many other conditions associated with either pulmonary or cerebral pathology. It is also common in severe malaria, ${ }^{3}$ and studies in adults $^{4}$ and children ${ }^{5}$ have, as in childhood pneumonia and meningitis, stressed that the possible cause may be the syndrome of inappropriate antidiuretic hormone secretion (SIADH).

However, the diagnosis of SIADH is one of exclusion and the presence of renal impairment and hypovolaemia in particular are incompatible with the diagnosis. Renal impairment is said to be uncommon in African children with malaria ${ }^{6}$ although mild renal impairment has been described in Indian children with non-severe malaria. ${ }^{7}$ In adults, acute renal failure is a common serious complication of malaria ${ }^{6}$ and hypovolaemia, possibly Coulter Electronics), thick and thin blood films Giemsa stained and counted for asexual forms of $P$ falciparum (per 100 white blood cells or 500 red blood cells), sodium and potassium (CIBA-Corning, ion selective electrode), urea and creatinine (Beckman Instruments), osmolality (freezing point depression, Advanced Instruments), venous blood gas (CIBA-Corning), and blood glucose (Analox Instruments). An aliquot of the first urine passed after admission was collected with a urine collection bag for determination of urinary electrolytes (CIBA-Corning, flame photometer), osmolality and creatinine (Beckman Instruments), and urinalysis (Multistix, Bayer).

All children were weighed immediately on electronic scales giving values in increments of 
$10 \mathrm{~g}$ over a $25 \mathrm{~kg}$ range (Faraday). Children were treated with either intravenous quinine or intramuscular artemether as part of a concurrent randomised controlled trial, followed by pyrimethamine/sulphadoxine when aparasitaemic and able to drink. Additional treatment, given as required, included $50 \%$ dextrose as a slow bolus over $5 \mathrm{~min}$ to hypoglycaemic children (blood glucose $<2 \cdot 2 \mathrm{mmol} / \mathrm{l}$ ), and intravenous diazepam for treatment of seizures. Refractory seizures or status epilepticus were treated with either phenytoin or phenobarbitone. All children unable to localise a painful stimulus were treated with standard doses of benzylpenicillin and chloramphenicol until lumbar puncture, performed once the child could localise, had excluded meningitis.

All children were given maintenance intravenous fluids of $0.18 \%$ saline in dextrose at a rate of $75 \mathrm{ml} / \mathrm{kg} / 24 \mathrm{~h}$ irrespective of admission sodium. This supplied sodium at a minimum rate of $2.25 \mathrm{mmol} / \mathrm{kg} / 24 \mathrm{~h}$ compared to the recommended minimum daily intake of $0.7-2.5 \mathrm{mmol} / \mathrm{kg} / 24 \mathrm{~h} .{ }^{14}$ Transfusion of $20 \mathrm{ml} / \mathrm{kg}$ of whole blood or additional fluid as $0.9 \%$ saline was given for the management of severe anaemia with respiratory distress or dehydration respectively. Intravenous fluids were stopped as soon as the child was able to drink and all were then allowed to eat and drink freely. If frusemide was given with blood transfusion and a urine specimen had not yet been collected, the child was withdrawn from the study; children transfused but not receiving frusemide remained in the study.

Between 48 and $72 \mathrm{~h}$ after admission (hereafter referred to as day 2) each child was reweighed, blood was taken for electrolytes, urea, creatinine, and osmolality, and a second aliquot of urine was collected for determination of electrolytes. Weights were repeated on the day of discharge or the fifth inpatient day. If the child remained hyponatraemic (plasma sodium $<135 \mathrm{mmol} / \mathrm{l}$ ) on day 2 electrolytes were measured on the fifth inpatient day, or the day of discharge if this was sooner. The normal weight of any child was assumed to be the weight on the fifth day, or on discharge once there was a normal plasma sodium (135-145 $\mathrm{mmol} / \mathrm{l})$ and the child was eating and drinking freely. The percentage weight change from admission to discharge was calculated as the weight difference $\div$ discharge weight $\times 100$.

The study was carried out as part of an ongoing programme investigating the pathophysiology of severe malaria, approved by Kenyan national scientific and ethics committees. Children were enrolled only after informed consent had been obtained from the accompanying parent or guardian.

\section{STATISTICS}

Continuous variables were analysed using either one way analysis of variance to compare groups, or the paired $t$ test where sequential results were available in surviving patients. Proportions were compared using Pearson's $\chi^{2}$ or Fisher's exact test. A p value of 0.05 was considered significant. All analyses were performed using the software package SPSS.

\section{Results}

One hundred and sixty four children were eligible for inclusion during the study period but seven died before completing the admission procedure and 25 were subsequently withdrawn from analysis (11 had received either frusemide or mannitol before urine collection; six had no urine collected; three did not have documentation of admission or discharge weight, and one each had salicylate toxicity, no admission creatinine, a prolonged clinical course because of sulphadoxine/pyrimethamine resistance, pretreatment with intravenous fluids, and severe neurological sequelae requiring nasogastric feeding). Results on 132 children ( $80 \%$ of those initially eligible), of whom eight died, are presented.

The mean age of the children in the study was 30 (SEM 2.1) months, and 53\% were male. In $72(55 \%)$ the admission sodium was less than $135 \mathrm{mmol} / \mathrm{l}$ and in 27 of these $(21 \%$ overall) it was less than or equal to $130 \mathrm{mmol} / \mathrm{l}$, while in four (3\%) it was more than 145 $\mathrm{mmol} / \mathrm{l}$. Five children were hyponatraemic on discharge (sodium $<135 \mathrm{mmol} / \mathrm{l}$ ). These children were not considered to have reached the prospectively defined 'normal' weight and they have been excluded from any analysis including weight change. Of these, three were discharged with a rising plasma sodium, weight gain, and fractional sodium excretion $<0.35$ on day 2 , implying partial correction of salt and water depletion. The other two probably developed iatrogenic hyponatraemia during their inpatient care since both were admitted with normal plasma sodium but plasma urea out of proportion to plasma creatinine $(8.0 \mathrm{mmol} / 1$ v $60 \mu \mathrm{mol} / 1$ and $26.8 \mathrm{mmol} / 1 v$ $120 \mu \mathrm{mol} / \mathrm{l}$ ) before administration of intravenous fluids.

In children admitted with normal plasma sodium (135-145 mmol/1), mild hyponatraemia (sodium 131-134 mmol/l), or severe hyponatraemia (sodium $130 \mathrm{mmol} / \mathrm{l}$ ), there were no differences in mean inpatient stay (3.9 $\mathrm{d}$ in each group), number with cerebral malaria $(41 \%, 33 \%$, and $32 \%$ respectively), or number who died $(7 \%, 4 \%$, and $7 \%$ respectively). Table 1 summarises further the basic laboratory and clinical information on presentation for the three groups. Children presenting with severe hyponatraemia were older than those with normal sodium (mean ages $40 \cdot 1$ and 24.4 months respectively, $p=0.005$ ), had higher mean haemoglobin $(7.2$ v $5.0 \mathrm{~g} / \mathrm{dl}$, $\mathrm{p}<0.001)$ and higher mean glucose $(7.47 v$ $4.21 \mathrm{mmol} / \mathrm{l}, \mathrm{p}<0.001$ ), but lower mean urea (3.46 v $5.84 \mathrm{mmol} / \mathrm{l}, \mathrm{p}=0.006)$ and lower mean weight gain $(2.4 \% v 4.3 \%, \mathrm{p}=0.03)$. No significant differences were observed between groups for mean urine osmolality or geometric mean urine sodium on admission.

Of survivors who reached normal weight, 30 $(25 \%)$ gained $\geqslant 5 \%$ and $<10 \%$ in weight, and seven $(6 \%)$ gained $\geqslant 10 \%$ in weight, signifying moderate and severe dehydration respectively. 
Table 1 Characteristics of children with hyponatraemia on admission. Values are means (95\% confidence intervals)

\begin{tabular}{|c|c|c|c|c|c|c|}
\hline & \multirow{2}{*}{$\begin{array}{l}\text { Group } 1 \\
\text { (sodium 135- } \\
145 \mathrm{mmol} / \text { ) } \\
n=56\end{array}$} & \multirow{2}{*}{$\begin{array}{l}\text { Group } 2 \\
\text { (sodium 131- } \\
134 \mathrm{mmol} \text { ) } \\
n=45\end{array}$} & \multirow{2}{*}{$\begin{array}{l}\text { Group } 3 \\
\text { (sodium } \leqslant 130 \\
\text { mmoll) } \\
n=27\end{array}$} & \multicolumn{3}{|c|}{ Comparison of groups } \\
\hline & & & & $1 \times 2$ & $1 \times 3$ & $2 \times 3$ \\
\hline $\begin{array}{l}\text { Mean age (months) } \\
\text { Mean haemoglobin }(\mathrm{g} / \mathrm{dl}) \\
\text { Mean log parasites } \\
\text { Mean urea }(\mathrm{mmol} / \mathrm{l}) \\
\text { Mean creatinine }(\mu \mathrm{mol} / \mathrm{l}) \\
\text { Mean glucose }(\mathrm{mmol} / \mathrm{)}) \\
\text { No with hypoglycaemia } \\
\text { Mean urine osmolality }\end{array}$ & $\begin{array}{c}24 \cdot 4(19 \cdot 7 \text { to } 29 \cdot 2) \\
5 \cdot 0(4 \cdot 3 \text { to } 5 \cdot 6) \\
4 \cdot 68(4 \cdot 45 \text { to } 4 \cdot 91) \\
5 \cdot 84(4 \cdot 69 \text { to } 6 \cdot 97) \\
67 \cdot 1(59 \cdot 7 \text { to } 74 \cdot 6) \\
4 \cdot 21(3 \cdot 56 \text { to } 4 \cdot 85) \\
16(26 \%)\end{array}$ & $\begin{array}{l}29.4(22 \cdot 0 \text { to } 36 \cdot 8) \\
6.0(5 \cdot 2 \text { to } 6.9) \\
4.91(4.65 \text { to } 5 \cdot 18) \\
4.99(3.90 \text { to } 6.08) \\
64.4(54 \cdot 1 \text { to } 74 \cdot 8) \\
5.29(4.51 \text { to } 6 \cdot 06) \\
5(12 \%)\end{array}$ & $\begin{array}{l}40 \cdot 1(28 \cdot 1 \text { to } 52 \cdot 0) \\
7 \cdot 2(6 \cdot 0 \text { to } 8 \cdot 1) \\
4.91(4 \cdot 59 \text { to } 5 \cdot 24) \\
3 \cdot 46(2 \cdot 74 \text { to } 4 \cdot 17) \\
61 \cdot 8(51.5 \text { to } 72 \cdot 1) \\
7.47(6 \cdot 27 \text { to } 8 \cdot 68) \\
1(4 \%)\end{array}$ & $\begin{array}{l}\text { NS } \\
p=0.04 \\
N S \\
\text { NS } \\
N S \\
p=0.04 \\
p=0.03^{2}\end{array}$ & $\begin{array}{l}\mathrm{p}=0.005 \\
\mathrm{p}=0.001 \\
\mathrm{NS} \\
\mathrm{p}=0.007 \\
\mathrm{NS} \\
\mathrm{p}<0.001 \\
\mathrm{p}=0.009^{2}\end{array}$ & $\begin{array}{l}\mathrm{NS} \\
\mathrm{NS} \\
\mathrm{NS} \\
\mathrm{NS} \\
\mathrm{NS} \\
\mathrm{p}=0.001 \\
\mathrm{NS}^{2}\end{array}$ \\
\hline $\begin{array}{l}(\mathrm{mmol} / \mathrm{l}) \dagger \\
\text { Mean urine sodium }\end{array}$ & 489 (442 to 535$)$ & 432 (383 to 481$)$ & 429 (359 to 498$)$ & NS & NS & NS \\
\hline $\begin{array}{l}(\mathrm{mmol} / \mathrm{l})^{1} \\
\text { Mean weight change }(\%)^{\star}\end{array}$ & $\begin{array}{l}31(23 \text { to } 43) \\
4 \cdot 3(3 \cdot 4 \text { to } 5 \cdot 2)\end{array}$ & $\begin{array}{l}32(23 \text { to } 45) \\
3 \cdot 3(2 \cdot 3 \text { to } 4 \cdot 2)\end{array}$ & $\begin{array}{l}21(13 \text { to } 36) \\
2 \cdot 4(0.6 \text { to } 4 \cdot 2)\end{array}$ & $\begin{array}{l}\text { NS } \\
\text { NS }\end{array}$ & $\begin{array}{l}\text { NS } \\
p=0.03\end{array}$ & $\begin{array}{l}\text { NS } \\
\text { NS }\end{array}$ \\
\hline
\end{tabular}

*All survivors excluding five who failed to reach 'ideal weight', $n=50,42$, and 23 for groups 1,2 , and 3 respectively.

†Excluding children treated with a bolus of glucose for hypoglycaemia the differences between groups remained insignificant, osmolalities 506, 437, and 432 for groups 1,2 , and 3 respectively.

${ }^{1}$ Geometric means. ${ }^{2}$ Fisher's exact test.

A further $27(22 \%)$ gained between $3 \%$ and $4.9 \%$ in weight and three $(3 \%)$ lost $\geqslant 3 \%$ in weight $(n=119)$. In all survivors (including those discharged with hyponatraemia) there were highly significant decreases in creatinine (65.8 $v 37.9 \mu \mathrm{mol} / 1,95 \%$ confidence interval (CI) for difference 22.0 to $33.8 \mu \mathrm{mol} / \mathrm{l}$, $\mathrm{p}<0.001)$, urea $(5.5 v 1.9 \mathrm{mmo} / \mathrm{l}, 95 \% \mathrm{CI}$ for difference 2.7 to $4.4 \mathrm{mmol} / \mathrm{l}, \mathrm{p}<0.001$ ), and geometric mean fractional sodium excretion $(0.60 v 0.11,95 \%$ CI for difference 0.13 to $0.27, p<0.001)$ during the inpatient stay. Urinalysis was performed on admission in 123 children, with $46 \%$ of samples positive for blood (half of these $=+++$ ), $53 \%$ positive for protein $(+/++)$, and $37 \%$ positive for both. Glycosuria $(+)$ was detected in one child, who had received a bolus of intravenous glucose. Abnormal urinalysis was not related to hyponatraemia, high parasitaemia, or raised urea or creatinine. The prevalence of hypokalaemia (potassium $<3.5 \mathrm{mmol} / \mathrm{l}$ ) in survivors increased from $14 \%$ on admission $(17 / 124)$ to $39 \%(48 / 124)$ on day 2 , with 38 children becoming hypokalaemic after admission. Only one child with hypokalaemia on admission had a mild metabolic alkalosis.

Children who were dehydrated (those gaining at least $5 \%$ in weight) had higher mean urea $(6.1 v 4.5 \mathrm{mmol} / \mathrm{l}, \mathrm{p}=0.02)$, higher mean sodium (137.2 $v 134.0 \mathrm{mmol} / \mathrm{h}, \mathrm{p}=0.004)$, and lower base excess on venous gas $(-12 \cdot 1 v$ $-8.0, p=0.01)$ than children with a smaller weight gain (table 2). However, mean creatinine and mean urine osmolality on admission were not significantly different between these groups. Of the four hypernatraemic children, all of whom survived, two were severely dehydrated $(>10 \%)$ and one moderately dehydrated $(5-10 \%)$. These children were resuscitated with normal saline, in addition

Table 2 Admission investigations in children with and without dehydration. Values are means (95\% confidence intervals)

\begin{tabular}{lccl}
\hline & $\begin{array}{c}\text { Children with }<5 \% \\
\text { weight gain }(n=82)\end{array}$ & $\begin{array}{l}\text { Children with } \geqslant 5 \% \\
\text { weight gain }(n=37)\end{array}$ & Significance \\
\hline Haemoglobin $(\mathrm{g} / \mathrm{dl})$ & $6 \cdot 0(5 \cdot 4$ to $6 \cdot 7)$ & $5 \cdot 2(4 \cdot 2$ to $6 \cdot 0)$ & $\mathrm{NS}$ \\
Urea $(\mathrm{mmol} / \mathrm{h})$ & $4 \cdot 5(3.9$ to $5 \cdot 2)$ & $6 \cdot 1(4 \cdot 6$ to $8 \cdot 6)$ & $\mathrm{p}=0.02$ \\
Creatinine $(\mu \mathrm{mol} / \mathrm{l})$ & $61 \cdot 1(54 \cdot 7$ to 67.9$)$ & $72 \cdot 8(61.5$ to 84.1$)$ & $\mathrm{NS}$ \\
Sodium $(\mathrm{mmol} / \mathrm{l})$ & $134.0(132.9$ to 135.1$)$ & $137 \cdot 2(135.0$ to $139 \cdot 4)$ & $\mathrm{p}=0.004$ \\
Base excess & $-8.0(-9.8$ to $-6 \cdot 2)$ & $-12 \cdot 1(-14.8 \text { to }-9 \cdot 4)^{2}$ & $\mathrm{p}=0.01$ \\
\hline
\end{tabular}

${ }^{1} n=73,{ }^{2} n=36$. to receiving maintenance $0 \cdot 18 \%$ saline in dextrose, to ensure appropriate correction of water and volume depletion without a precipitate fall in the plasma sodium.

Of the 68 surviving children who had been hyponatraemic on admission, four had a calculated plasma osmolality ${ }^{15}$ greater than $280 \mathrm{mmol} / \mathrm{l}$ but 64 fulfilled the basic biochemical requirements of SIADH, recently defined as hyponatraemia (sodium $<135$ $\mathrm{mmol} / \mathrm{l}$ ) in the presence of plasma hypoosmolality $(<280 \mathrm{mmol} / \mathrm{l})$ and urine that is less than maximally dilute $(>100 \mathrm{mmol} / \mathrm{l}) .{ }^{16}$ However, this definition is only valid in the absence of hypovolaemia, hypotension, renal, adrenal or thyroid insufficiency, congestive cardiac failure, nephrosis, cirrhosis, or other disorder resulting in generalised oedema. In addition, plasma urea and creatinine should be normal while urinary sodium is usually greater than $20 \mathrm{mmol} / 1 .{ }^{16}$ Thus SIADH could confidently be excluded retrospectively in a further 41 hyponatraemic survivors by one or more of the following features: dehydration $(n=15)$, an admission urinary sodium of $<20$ $\mathrm{mmol} / \mathrm{l}(\mathrm{n}=22)$, or a $50 \%$ reduction in creatinine (creatinine difference $\div$ admission creatinine $\times 100)$ during admission $(n=18)$. Of the remaining 23 children, a further 18 were unlikely to have SIADH for one or more of the following reasons: severe anaemia (haemoglobin $\leqslant 5 \mathrm{~g} / \mathrm{dl}, \mathrm{n}=10$ ), metabolic acidosis in venous blood (base excess $\leqslant-10$, $\mathrm{n}=8$ ), and more than $50 \%$ reduction in urea from admission today 2 (urea difference $\div$ admission urea $\times 100, n=11)$. This left five surviving children in whom SIADH was a possible cause of hyponatraemia, and even in these it resolved rapidly with our standard fluid management (outlined above). Furthermore measured plasma osmolality was $>280$ $\mathrm{mmol} / \mathrm{l}$ in two and urinalysis was positive for blood in four and for protein in two of these five children, making mild renal dysfunction difficult to exclude.

Six dehydrated hyponatraemic children had urinary sodium greater than $20 \mathrm{mmol} / \mathrm{l}$ on admission. In all six there was profound metabolic acidosis (base excess $\leqslant 14$ ). In three, severe anaemia (haemoglobin $<5 \mathrm{~g} / \mathrm{dl}$ ) was associated with hyperlactataemia (whole blood lactate $>10 \mathrm{mmol} / \mathrm{l}$ ), while the other three had 
a normal lactate $(<2 \mathrm{mmol} / \mathrm{l})$ but plasma creatinine values that fell by $\geqslant 150 \%$ during admission. These findings suggest the presence of inappropriate renal tubular sodium loss on admission in these children.

\section{Discussion}

In the absence of a true gold standard for dehydration, acute changes in weight are often used. ${ }^{1718}$ We prospectively defined normal weight as the weight on the fifth day, or at discharge if this was sooner, in a child with a normal plasma sodium (135-145 $\mathrm{mmol} / \mathrm{l})$ who was eating and drinking freely. While some increase in dry weight could have occurred over such a short time, weight changes were more likely to have reflected changes in fluid balance. Since follow up weight measurements were not done an alternative explanation is that weight gain in hospital reflected pathological fluid retention. Acute malaria results in a fall in haemoglobin, often for several days after adequate treatment ${ }^{19}$ and the compensatory requirement for increased cardiac output could result in fluid retention. Secondly, since characteristics of falciparum malaria include adherence to endothelial cells and since severe infection is associated with high levels of circulating inflammatory mediators, ${ }^{20}$ it is possible that capillary leak secondary to endothelial damage would result in fluid retention. However, we consider a normal clinical examination on discharge (no clinical oedema) of a well child makes dehydration the most likely explanation for weight gain. Thus $31 \%$ of children achieving normal weight were at least moderately dehydrated on admission by our definition ( $\geqslant 5 \%$ weight gain).

Despite the fact that $55 \%$ of children were hyponatraemic on admission and that many of these would have fulfilled the basic biochemical requirements of SIADH, examination of urine and availability of sequential investigations and weights made the diagnosis in survivors highly unlikely in retrospect. In particular, weight gain in association with a rising sodium is incompatible with SIADH. Thus, although the causes of hyponatraemia in children who died could not be determined reliably by the methods we used, it is probable that SIADH is also uncommon in this group. Hyponatraemia (in those who died and those who survived) was associated with increased age, higher haemoglobin, higher blood glucose, lower urea, and smaller weight gain (that is, less dehydration). It thus probably results from an appropriate hormonal response to the loss of electrolyte and fluid in sweat, vomit, and stool in children treated at home with fluids of low electrolyte content (which include breast milk). We speculate that older children mount a better stress response to malaria infection, including higher levels of gluconeogenic and antidiuretic hormones. Alternatively, it may be easier to maintain fluid intake at home in older children in whom complications such as severe anaemia and hypoglycaemia (but not encephalopathy) may take longer to develop.
In surviving children, obvious falls were observed in plasma creatinine and urea during admission, but the clinical significance of this is less clear cut. Oliguric renal failure was not observed in survivors and although 13 children had admission creatinine of at least $120 \mu \mathrm{mol} / 1$ normal values were rapidly achieved with appropriate fluid resuscitation. Obviously, the extent of renal impairment could not be determined in children who died. Our results support a role for hypovolaemia (dehydration) in the mild acute renal impairment found in survivors of severe childhood malaria. This is consistent with low creatinine clearances and low central venous pressures found in a group of critically ill children with malaria (M C English et al, unpublished data) and with theories on the pathogenesis of renal failure in adults. ${ }^{8}$

Malaria may also directly affect renal function, since a sodium losing state was apparent in at least six children and admission urine osmolality was inappropriately low in some dehydrated children, suggesting the presence of a urine concentrating defect. Glomerular changes frequently occur in adult malaria ${ }^{8}$ and may account for the presence of blood and protein in the urine of many children in this study. Alternatively, haemoglobinuria accompanying haemolysis may have been the cause. As urine microscopy was not performed, we could not determine which cause predominated. Similarly, since the presence of haematuria or proteinuria was much more common than anticipated, routine follow up was not part of the study design. Thus how long abnormalities persisted in affected children is unknown. However, the observed abnormalities appeared to have little clinical significance if children were adequately resuscitated with fluids, although in prostrated or comatose children not given adequate electrolyte and fluid replacement intrinsic renal impairment might result in a worsening of both hypovolaemia and renal function.

Our study has several implications for the management of children with severe malaria. Firstly, dehydration is relatively common and requires treatment. Secondly, in children who are hyponatraemic sodium depletion which exceeds water depletion is much more likely than SIADH. Thus a general policy of fluid restriction for children in coma may contribute to renal impairment. If hypotonic solutions, or isotonic solutions mainly comprising glucose, are used when restricting fluids in children they may exacerbate hyponatraemia in those who have an appropriate antidiuretic hormone response. This may contribute to raised intracranial pressure and predispose to seizures. ${ }^{21}$ Thirdly, we did not expect to find hypokalaemia so often in these children, most of whom had been on intravenous fluids for less than 24 hours, although mild diarrhoea and vomiting are frequently associated with malaria in children. Early potassium supplementation should therefore be considered, particularly in those with metabolic acidosis, since unnoticed hypokalaemia may cause cardiac dysrhythmias, worsen renal tubular function, and, by impairing skeletal muscle contractility, contribute to late respiratory arrests. 
The current view is that fluid should be restricted in children with pneumonia and meningitis in developing countries ${ }^{12}$ if they have no overt signs of dehydration, because of the risk of SIADH. We suggest that in our patients appropriate antidiuretic hormone secretion prevented dehydration (and thus its clinical signs). This possibility needs to be investigated in pneumonia and meningitis in developing countries, in view of recent evidence that children with meningitis are relatively hypovolaemic. ${ }^{22}$ Adequate sodium given to children with appropriate antidiuretic hormone, even in modest fluid volumes, is likely to resolve hyponatraemia. If SIADH is present, any excess sodium given results in nothing worse than an increase in urinary sodium excretion. ${ }^{23}$ Sodium restriction (often inadvertent) should not be the inevitable consequence of fluid restriction, and SIADH, which is probably uncommon, should remain a diagnosis of exclusion in severe childhood malaria.

This work is published with the permission of Dr D Koech, Director of the Kenya Medical Research Institute. The authors would like to thank Professor G Haycock and Dr L Baker for advice and B Lowe, M Mosobo, M Mwakala and the nurses and clinicians of the KEMRI reseach unit and Kilifi District Hospital for their help during the study. Dr K Marsh is a Wellcome Trust Senior Research Fellow in clinical science. All work was carried out on site at the CRC, KEMRI Kilifi Unit, and Kilifi District Hospital, Kilifi, Kenya.

1 Dhawan A, Narang A, Singhi S. Hyponatraemia and the inappropriate $\mathrm{ADH}$ syndrome in pneumonia. Ann Trop Paediatr 1992; 12: 455-62.

2 Shann F, Germer S. Hyponatraemia associated with pneumonia or bacterial meningitis. Arch Dis Child 1985; 60: $963-6$.

3 Miller L, Makaranond P, Sitprija V, et al. Hyponatraemia in malaria. Ann Trop Med Parasitol 1967; 61: 265-79.

4 Holst F, Hemmer C, Kern P, Dietrich M. Inappropriate secretion of antidiuretic hormone and hyponatraemia in severe falciparum malaria. Am f Trop Med Hyg 1994; 50: $602-7$.

5 Ogunye O, Gbadebo AO. Syndrome of inappropriate antidiuretic hormone secretion (SIADH) in measles and malaria infections. Trop Geogr Med 1981; 33: 165-8.

6 Warrell DA, Molyneux ME, Beales PF. Severe and complicated malaria. Trans $R$ Soc Trop Med Hyg 1990; 84 (suppl 2): $1-65$

7 Ahmad SH, Danish T, Faridi MA, Ahmad AJ, Fakhir S, Khan AS. Renal function in acute malaria in children. f Trop Pediatr 1989; 35: 291-4.

8 Boonpucknavig V, Sitprija V. Renal disease in acute Plasmodium falciparum infection in man. Kidney Int 1979; 16: 44-52.

9 Taylor T, Borgstein A, Molyneux M. Acid base status in paediatric Plasmodium falciparum malaria. $Q \mathcal{f} \mathrm{Med}$ 1993; 86: 99-109.

10 Kildeberg $P$. Metabolic acidosis in infantile gastroenteritis. Acta Paediatr Scand 1965; 54: 155-67.

11 Hendrickse R, Barr D, Matthews T. Paediatrics in the tropics. Oxford: Blackwell Scientific Publications, 1991.

12 Newton C, Kirkham F, Winstanley P, et al. Intracranial pressure in African children with cerebral malaria. Lancet 1991; 337: 573-6.

13 Marsh K, Forster D, Waruiru C, et al. Life threatening malaria in African children: clinical spectrum and simplified prognostic criteria. $N$ Engl $尹$ Med 1995; 332: 1399-404.

14 Campbell A, McIntosh N, eds. Forfar and Arneil's textbook of paediatrics. Edinburgh: Churchill Livingstone, 1992.

15 Gennari FJ. Serum osmolality: uses and limitations. $N$ Engl f Med 1984; 310: 102-5.

16 Kovacs L, Robertson G. The syndrome of inappropriate antidiuretic hormone secretion. Endocrinol Metab Clin North Am 1992: 21: 859-75.

17 Mackenzie A, Barnes G, Shann F. Clinical signs of dehydration in children. Lancet 1989; ii: 605-75.

18 Lapides J, Bourne R, MacClean L. Clinical signs of dehydration and extracellular fluid loss. $\mathscr{f} A M A 1965 ; 191$ : dehydra.

19 Abdalla $S$, Weatherall D, Wickramasinghe S, Hughes $M$. The anaemia of $\mathrm{P}$ falciparum malaria. $\mathrm{Br} \mathcal{f}$ Haematol 1980; 46: 171-83.

20 Kwiatowski D, Hill A, Sambou I, et al. TNF concentration in fatal cerebral, non-fatal cerebral and uncomplicated Plasmodium falciparum malaria. Lancet 1990; 336: 1201-4.

21 Andrew $R$. Seizure and acute osmotic change: clinical and neurophysiological aspects. F Neurol Sci 1991; 101: 7-18.

22 Powell K, Sugarman L, Eskenazi A, et al. Normalization of plasma arginine vasopressin concentrations when children with meningitis are given maintenance plus replacement with meningitis are given maintenance plus

23 Bartter F, Schwartz W. The syndrome of inappropriate secretion of antidiuretic hormone. Am f Med 1967; 42: 790-805. 